\title{
Undoing the gaps in quality, cost, and value
}

Thomas A. D’Amico, MD

\author{
From the Division of Thoracic Surgery, Department of Surgery, Duke University Medical Center, Durham, NC. \\ Disclosures: Author has nothing to disclose with regard to commercial support. \\ Received for publication Sept 3, 2017; accepted for publication Sept 8, 2017; available ahead of print Oct 4, 2017. \\ Address for reprints: Thomas A. D'Amico, MD, Gary Hock Endowed Professor of Surgery, Chief, Section of \\ General Thoracic Surgery, Duke University Medical Center, DUMC Box 3496, Duke South, White Zone, \\ Room 3589, Durham, NC 27710 (E-mail: thomas.damico@duke.edu). \\ J Thorac Cardiovasc Surg 2018;155:1211 \\ $0022-5223 / \$ 36.00$ \\ Copyright (c) 2017 by The American Association for Thoracic Surgery \\ https://doi.org/10.1016/j.jtcvs.2017.09.022
}

The process of analyzing cost-effectiveness in thoracic surgery has been insufficient: the quality and quantity of studies have been inadequate, and even the most persuasive studies seem to be ignored, as evidenced by enormous practice variation in the United States. ${ }^{1}$ The demand for these analyses is also seemingly insufficient. Medicare does not include cost-effectiveness in decisions to cover new therapies. Opponents of cost-effectiveness analysis characterize the process both as limiting provider decision making and as rationing care. The United States spends much more of its national income on health care than other countries, at least in part because of a lack of adherence to the process and results of cost-effectiveness research. ${ }^{1}$

Many agree that the national quality agenda to improve American health care is insufficient. ${ }^{2}$ Surgeons will soon be judged on the quality of surgical care without validated quality measures and without validated cost assessment processes. It is incumbent on us to engage in the process, including developing an awareness of the goals and accomplishment of quality-based organizations such as the National Quality Forum, to contribute to the development of and adherence to evidence-based guidelines, such as those published by The American Association for Thoracic Surgery and the National Comprehensive Network, and to assess and measure our own outcomes.

Even analyses of limited scope may potentially improve practice. The study by Richardson and colleagues ${ }^{3}$ in this issue of the Journal analyzes the cost per case variations between 2 surgeons in an academic medical center with respect to specific surgeon choices regarding intraoperative equipment and supplies. It concludes that these choices are the main driver of cost variation between the 2 surgeons (whose outcomes were similar). ${ }^{3}$ Despite the limited scope of this study, the concept of such comparisons is critical if we are soon to make judgments regarding

\section{References} 376:203-5.

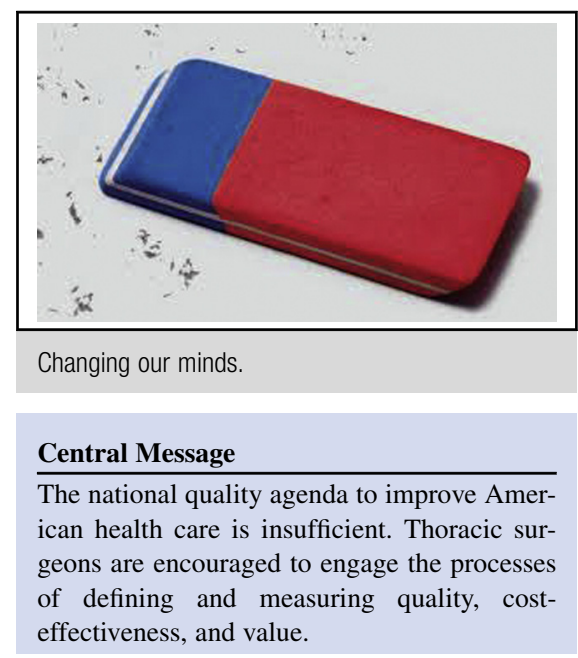

See Article page 1267.

the cost-effectiveness of robotics versus thoracoscopic thoracic surgery, or regionalizing some surgical procedures (such as esophagogastrectomy), or implementing other new technologies into surgical practice. The specific conclusions of this study are not as important as the process in which surgeons are aware of their own cost per case. For example, in the hands of most surgeons, if the energy source limits the staple usage to 1 to 2 loads, it is cost neutral or cost superior. In addition, the study measures the cost-effectiveness of 2 surgeons of different levels of experience, which may be more important in limiting cost than other measured variables. In any case, this study helps to emphasize that thoracic surgeons should engage in the process of defining and measuring quality, costeffectiveness, and value.

1. Neumann PJ, Sanders GD. Cost-effectiveness analysis 2.0. N Engl J Med. 2017;

2. Jha AK. Resetting the nation's health care quality agenda. NEJM Catalyst. Available at: http://catalyst.nejm.org/resetting-nations-health-quality-agenda/. Accessed September 3, 2017.

3. Richardson MT, Backhus LM, Berry MF, Vail DG, et al. Intraoperative costs of VATS lobectomy can be dramatically reduced without compromising outcomes. J Thorac Cardiovasc Surg. 2018;155:1267-77. 